\title{
Application Strategy of Modern Network Technology in Higher Vocational Teaching Activities
}

\author{
Wenping Ouyang \\ Hunan Radio and TV University, Changsha, CHINA
}

Received 16 July 2017 - Revised 19 August 2017 • Accepted 1 October 2017

\begin{abstract}
The pace of the development of contemporary science and technology is accelerating, and the multimedia assisted instruction technology with computer as the core has become an indispensable teaching means in higher vocational colleges (HVCs), and also an important mark of educational reform in HVCs in China. The development of modern network technology provides a strong impetus to the teaching reform in HVCs. This paper analyzes the research status of modern network technology application in domestic and overseas higher vocational education (HVE). It was found that the research on the application of modern network technology in HVE in China has a certain gap with that in overseas countries, especially the developed countries. Meanwhile, problems also exist that multimedia technology is too backward, the quality of CAI courseware cannot be guaranteed, and the interaction between teachers and students lacks, etc. Focusing on these problems, we suggest the following measures. First, vigorously strengthening the construction of campus information environment, establishing strict introduction and management systems of network facilities, strengthening the construction requirements of software teachers, and enhancing the propaganda of modern network technology. Second, integrating information technology with curriculum teaching, focusing on the inspection and verification of theoretical knowledge and application results, and improving the effect of students' knowledge acquisition. Third, enhancing the modernization of teaching technology in HVE, improving the memory effect of students' knowledge, thus arousing the enthusiasm of learning and teaching enthusiasm, and solving the lack of interaction between teachers and students, through the service function provided by network information technology. The starting point of optimizing the atmosphere of teaching activities in HVC is from these three aspects. Improve the application level of modern network technology in higher vocational teaching activities in China, and establish the application strategy of modern network technology in higher vocational teaching activities.
\end{abstract}

Keywords: teaching reform, modern network technology, application strategy

\section{INTRODUCTION}

Facing 21th Century, China has already paid attention to the integration of science, technology and education, and higher vocational colleges (HVCs) have made great efforts to build a modern teaching environment. Modern network technology has become an integral part of higher vocational teaching activities (HVTA), and the effect of network technology has a direct impact on the quality of teaching activities (Cheng, 2015). The rapid development of digital media technology has changed the information dissemination and acceptance habits of young students, which requires changing teaching ideas and teaching methods in education (Collins, Burke, Martindale, et al. 2015).

(C) Authors. Terms and conditions of Creative Commons Attribution 4.0 International (CC BY 4.0) apply. Correspondence: Wenping Ouyang, Hunan Radio and TV University, Changsha, 410004, China, +86 13873190476. ouyanghnrtu@126.com 


\section{Contribution of this paper to the literature}

- The content of the current research was clearly explained, the collection and collation of research materials of domestic and overseas literature were relatively comprehensive;

- Concrete improvement strategies were presented for the problems of modern network technology in HVTA;

- The analysis of the problem was in-depth, and summarization was pertinent.

Research on the application of modern network technology in higher vocational education (HVE) in China has a certain gap with that in overseas countries, especially the developed countries. The application of multimedia technology only stays at the display level of teaching content, and it can seldom display the full content of teaching activities through the function of multimedia teaching technology. In the current teaching activities in HVCs, there are still many quality problems in the design and manufacture of CAI courseware, and just the basic theoretical knowledge is presented to the students in a way of presentation. Such CAI courseware is just a kind of writing with new pictures on the blackboard, with very little inspiration for students. The teaching function of courseware is very difficult to be displayed in front of students and teachers. In the process of using modern network technology to carry out teaching activities, there are still serious problems of lacking interaction between teachers and students. Modern network technology has not created the teaching atmosphere of mutual aid, and the educational function of modern network technology has not been fully demonstrated. Focusing on these problems, this study provided detailed solutions (Curran, Matthews, Fleet, et al. 2017; Connell, 2015).

\section{REVIEW OF CURRENT RESEARCH}

\section{Domestic Related Research Status}

With the arrival of the 21th Century, the Ministry of education took the lead in putting forward "the application of modern educational technology in the field of vocational education", and universities across the country have responded positively. In 2006, the project "the application of modern information technology in the cultivation of students' autonomous learning ability" was established by the Henan Provincial Department of Education. Career Technical College in Heilongjiang, Daqing, has undertaken the research project "the application and development of modern educational technology in the construction of teaching materials for vocational education". These projects analyzed the application direction of modern network technology in HVC teaching activities from several perspectives, and laid a solid theoretical foundation for the reform of HVE and modernization (Chen, 2017; Gai, 2015; Cui, 2015).

Liping $\mathrm{Yu}$ carried out related research on the impact of modern network technology in HVE, and considered that the application of modern network technology would have double influences in the fields of HVE, scientific research and management, with both advantages and drawbacks, and the drawbacks lied in that the modern network technology was too backward (Luque, Marcenaro-Gutiérrez, López-Agudo, 2015). Hong Qin carried out related research from the aspects of teaching organization and teaching methods, and believed that the application of modern network technology could improve the flexibility and diversity of teaching activities, but the content of the teaching structure was too simple. Peikang Zhu focused on the application of modern network technology in teaching activities in HVC and conducted systematic research, and it was considered that although the teaching technology had been applied, there was still a sense of distance between students and teachers, pointing out a new direction for the application of modern network technology in HVC in China (Chen, Sun, Chai, et al. 2016).

\section{General Situation of Foreign Research}

The United States was the first country in the world to use information technology in education. As early as the late 90s of the last century, it had been worked out the plan "Prepare every student in the United States for the coming twenty-first Century: meet the challenge of information literacy", and developed a series of reforms for the education of software, hardware, connectivity, professional integration. Back in the early 90s of the last century, 
Table 1. Regression equation fitting

\begin{tabular}{ccccc}
\hline Model & $\mathbf{R}$ & R-Square & Adjusted R-Square & Deviation of standard estimate \\
\hline 1 & $0.872 a$ & 0.85 & 0.913 & 0.3074 \\
\hline
\end{tabular}

Kenneth C. Green of Clement University put forward the viewpoint of the development of campus informatization, and established the Campus Computing Project. The research of this project has become the focus of world attention, and has provided an important theoretical reference for other countries to apply modern network technology in education (Kaymak, Winemiller, Akin, et al. 2015). Mr. Mery, Pamela M took San Francisco Institute as the studied object, and carried out research on the integration of modern network technology and student service system and how to correctly apply modern network technology. In the research results, three major measures were proposed. First, the development of education must be supported by powerful hardware. Second, more modern network technology application opportunities should be provided to students and teachers. Third, modern educational technology should build a sustainable planning system. These research results provided a good theoretical reference for the application of modern network technology in teaching activities in HVCs in China (Liu, Zhang, Shi, et al. 2015).

\section{METHODOLOGIES}

Comparing the application of modern network technology in the teaching activities of HVCs in China with the results of foreign research, the multimedia technology lags behind. These problems will directly lead to the difficulties in playing the educational value and educational role in HVC teaching activities for modern network technology. In this study, linear regression model was adopted for analysis.

Let $\zeta$ be the education quality of HVCs, $p_{a}$ represent multimedia technology is too backward, $p_{\max }$ represent the quality of CAI courseware cannot be guaranteed, and $p_{\min }$ represent the lack of interaction between teachers and students is serious. The correlation index can be obtained.

$$
\zeta=\frac{p_{\max }-p_{\min }}{p_{a}}
$$

Therefore, the application model of modern network technology in HVTA can be concluded:

$$
\lambda \leq \frac{p_{r} F^{-1}\left(\frac{b}{\gamma}\right)+p_{v} \int_{L}^{Q} f(x) d x-p_{h} \int_{L}^{Q} f(x) d x}{p_{r} Q_{m}\left(e^{I_{1} T}-\eta\right)}
$$

According to the above formula, and through statistical software SPSS18.0 regression analysis, the key factors for influence the teaching quality in HVCs as well as quantitative analysis were obtained, shapge the multiple regression model of the teaching quality in HVCs, shown as Table 1.

In Table 1, R represents the negative correlation coefficient between the explained variable and the explanatory variable, R-Square describes the judgment coefficient, Adjusted R-Square describes the adjusted judgment coefficient, and the last column represents the prediction error coefficient of the regression equation. The goodness of fit test can be reflected by Table 1, since the adjusted judgment coefficient is 0.913 , which is closed to 1 , Model 1 has relatively high fitting goodness, and the explanatory variable has a relatively large part that can be explained. The main problems of application of modern network technology in HVCs are:

\section{Multimedia Technology is too Backward}

It can be found from the above study that in teaching activities in HVCs in China, the most obvious problem in the application of modern network technology is that the multimedia technology is too backward. The application of multimedia technology only stays at the display level of teaching contents, and the content of teaching activities can rarely be fully displayed through the function of multimedia teaching technology. In this way, modern network technology can only be used as an alternative to traditional blackboard teaching, and it is difficult to achieve the purpose of modern educational technology, i.e., serving students, serving teachers and 
serving the classroom. The modernization of classroom teaching in HVCs can only be regarded as a superficial phenomenon, and substantial progress is difficult to be made (Wang, Wang, and Tian, 2015).

\section{The Quality of CAI Courseware is not Guaranteed}

CAI courseware is an important means to carry out multimedia teaching activities in HVCs. Many teachers believe that the novelty of the interface can improve the teaching effect in the design and production of CAI courseware. The content structure of the produced courseware is very simple, with basic theoretical knowledge presented to the students in a way of presentation. This kind of CAI courseware is only a blackboard writing with new pictures, and it has little enlightenment for students. It is difficult to arouse the enthusiasm of students to participate in classroom teaching activities (Yu, He, Zhong, et al. 2015). Therefore, modern network technology in classroom teaching activities in HVCs has not been substantially applied.

\section{Lack of Interaction between Teachers and Students is Serious}

In view of the research results of the application of modern network technology in teaching activities of HVCs in China, in the process of using modern network technology to carry out teaching activities, there are still serious problems of lacking interaction between teachers and students. Modern network technology has not created the teaching atmosphere of mutual aid, and the educational function of modern network technology has not been fully demonstrated. There is no obvious difference between the effect of current teaching activities and traditional teaching methods.

\section{RESULTS}

Facing the main problems in the application of modern network technology in teaching activities in HVCs, the solution mainly depends on the following three aspects. Set perfect application strategy of modern network technology. By exerting the educational function of modern network technology, the application value of teaching activities is improved.

\section{Vigorously Strengthen the Construction of Campus Information Environment}

Today, with the rapid development of network information technology, HVCs should make great efforts to apply modern network technology to teaching activities, and vigorously strengthen the construction of campus network environment. The following three aspects should be emphasized.

First, establish a strict introduction and management system for network facilities. In the aspect of the management system of network facilities, for the responsibility system of the maintenance and upgrade of facilities, the responsibility is fulfilled to a special person in charge, so that the network facilities are able to operate in real time, and the modern educational media can be more timely upgrade, solving the problem of backward modern educational media equipment in teaching activities.

Second, strengthen the construction of software teachers. In facing of the current problems in the application of modern educational technology in HVCs, the construction of the campus network environment should be strengthened so as to improve the construction of software teachers, and train a batch of teachers who can master the application of network technology, making the network resources able to be shared and utilized in teaching activities (Zhang, Zhu, Rong et al. 2015).

Third, enhance the propaganda of modern network technology. The propaganda of modern network technology can be carried out in three ways, namely, centered learning of leaders and teachers, inviting experts from the field to make special reports, and carrying out modern network technology training. Through the three ways, centralized exploration, expert guidance, special training, the leaders and teachers of HVCs are guilded to recognize the future of the application of modern network technology, providing an ideal environment for the better application of network information technology in teaching. 


\section{Integrating Information Technology with Curriculum Teaching}

The reason why the quality of CAI courseware in HVCs is not high is that teachers do not have a profound understanding of the essence of multimedia courseware, with only superficial understanding that courseware is made with just a few pictures or music, making courseware a means of teaching instead of writing on the blackboard. The teaching function of multimedia courseware is rarely recognized by teachers.

\section{Upgrading the Modern Level of Teaching Technology in HVE}

In the teaching activities of theoretical courses in HVCs, multimedia courseware teaching techniques are mainly selected. Through the multi-sensory stimulation the students' acquisition efficiency and teachers' knowledge transfer efficiency are improved, ensuring that students' eyes, ears, mouth and hands can participate in teaching activities, enhancing students' understanding, analysis and memory ability. Video teaching, picture teaching and audio teaching in multimedia courseware are combined with each other. Students perceive new knowledge at the same time through the two sensory systems of vision and hearing, which greatly improves the memory effect of the students' knowledge, and then promotes the enthusiasm of students' learning and teachers' teaching.

\section{DISCUSSION}

Modern network technology has been applied to different levels in HVCs, with endless effects, showing that modern network technology is irreplaceable in teaching activities to varying extents. The reason why modern network technology has the very good development prospect in the HVTA mainly lies in that the relationship between students and teachers can be close due to the transmission of network information and extensive information resources. The rich resources of teaching activities can meet the needs of students' in job practice, serving the whole link of the students' "learning" and the teachers' "teaching". In classroom teaching activities in HVCs, the application of network technology means not only to multimedia courseware, but the network information resource base is also an important modern network technology means. Through the rational application of network information resources, we can provide students with learning resources of more knowledge and knowledge fields, satisfing students' curiosity in their study activities. There is a cooperative relationship of knowledge acquisition and knowledge guidance between teachers and students. In this way, students and teachers can maintain more interactive process. This is the most direct method for HVCs to solve the problem of lacking interaction between teachers and students in the application of network technology in HVTA, and is the most ideal means to shorten the distance between teachers and students in teaching activities. Through the service function provided by the network information technology, the atmosphere of teaching activities in HVCs can be optimized.

\section{CONCLUSION}

In a word, we must take the construction of campus network environment as the first step in strengthening the application of modern network technology in HVTA, in order to create a good atmosphere for the application of modern network technology in teaching activities. As the application level of modern network technology is continuously strengthened, the educational function and value of the modern network technology should be exerted to provide good service for teaching activities.

\section{REFERENCES}

Chen, L. T. (2017). From education supply side comprehensive reform perspective to view higher vocational teaching innovation. Heilongjiang Researches on Higher Education, 3, 87-90.

Chen, Y., Sun, C. W., Chai, M. M, et al. (2016). A brief analysis of the professional construction of computer network in vocational and technical college of Tibet. Chinese Vocational and Technical Education, 10, 153-155. 
Cheng, Q. M. (2015). Research and application of software definition network technology in the security management of vocational college information network. Chinese Vocational and Technical Education, 2, 4851.

Collins, D., Burke, V., Martindale, A., \& Cruickshank, A. (2015). The Illusion of Competency Versus the Desirability of Expertise: Seeking a Common Standard for Support Professions in Sport. Sports Medicine, 45, 1-7.

Connell, J. (2015). Maintaining the Professionalization of Teaching in Higher Education: From Entry into the Profession to Lifelong Professional Development. Chemical Engineering Communications, 136, 67-75.

Cui, H. Y. (2015). The value dimension and realization mode of education of university network ideology politics in big data era. Heilongjiang Researches on Higher Education, 9, 33-36.

Curran, V., Matthews, L., Fleet, L., Simmons, K., Gustafson, D. L., \& Wetsch, L. (2017). A Review of Digital, Social, and Mobile Technologies in Health Professional Education. Journal of Continuing Education in the Health Professions, 37, 195-206.

Gai, K. R. (2015). Research and practice of informatization teaching in higher vocational courses. Chinese Vocational and Technical Education, 7, 18-21.

Kaymak, N., Winemiller, K. O., Akin, S., Altuner, Z., Polat, F., \& Dal, T. (2015). Stable isotope analysis reveals relative influences of seasonal hydrologic variation and impoundment on assimilation of primary production sources by fish in the Upper Yesilirmak River, Turkey. Hydrobiologia, 753, 131-147.

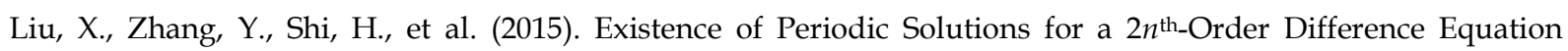
Involving-Laplacian. Bulletin of the Malaysian Mathematical Sciences Society, 38, 1107-1125.

Luque, M., Marcenaro-Gutiérrez, O. D., López-Agudo, L. A, (2015). On the potential balance among compulsory education outcomes through econometric and multiobjective programming analysis. European Journal of Operational Research, 241, 527-540.

Wang, Z. H., Wang, S. F., \& Tian, D. (2015). Network education teacher training based on Web theory system. Heilongjiang Researches on Higher Education, 5, 95-97.

Yu, M. H., He, P., Zhong, W. C, et al. (2015). Curriculum reform and practice of higher vocational college in computer network technology based on ability core and project course. Chinese Vocational and Technical Education, 9, 17-22.

Zhang, L. L., Zhu, L., Rong, F., et al. (2015). The association between online bullying and sleep disorders in higher vocational students. Chinese Journal of School Health, 36, 281-284.

\section{http://www.ejmste.com}

